\title{
Secchi Disc and Lago de la Republica, Eastern Paraguay
}

\author{
John A. Fitzpatrick ${ }^{1}$ and Juan F. Facetti-Masulli ${ }^{1,2}$ \\ 1. Hydroconsult, Charles de Gaulle 980 Asunción, Paraguay \\ 2. National University of Asunción, San Lorenzo, Paraguay
}

\begin{abstract}
The Secchi disc is used to obtain the water transparency D and a value for the attenuation coefficient $K t$ according to $K t=$ $C x . D^{-1}$ where $C$ is a factor estimated supposedly as a constant. Lago de la República, a small reservoir seated on basaltic residual soil laterites rich in secondary sesquioxides of $\mathrm{Fe}, \mathrm{Al}$, etc of the Alto Paraná Formation, after rainfalls incorporates significant amount of sediments rich in iron compounds easily hydrolyzed to produce colloidal hydrated ferric oxides. After some heavy rainfalls, advantage was taken to look for the effect of such compounds onto transparency and light attenuation coefficient of the lake water and their relationship.
\end{abstract}

Key words: Transparency, light attenuation coefficient, sediments, Lago de la República.

\section{Introduction}

Water clarity is related to the photonic climate in corpus aquae. The light level and spectrum of the down coming radiation is modified by the filtering characteristics of the water itself which absorbs more strongly the infrared and UV radiations than that radiation of 400-700 $\mathrm{nm}$ that represents approximately $1 / 3$ of the total $(38 \%)$ of solar radiation at sea level [1] and which coincides with the principal bands of absorption of radiation of the chlorophyl i.e., the PAR (photosynthetically active radiation). Besides, natural waters contain variable amounts of suspended materials as well as dissolved substances that attenuate the radiation by absorption, scattering etc. and affect its clarity/transparency.

Changes in transparency are thus due to several, simple/combined factors such as dissolved stained matter (gilvin), tripton (including constituent colloidal inorganic matter), phytoplankton etc. Average of total attenuation coefficient in the euphotic zone $\mathrm{Kt}$ is expressed approximately by $K t=k w+k g+k t r+k p h$, where $k w, k g, k t r, k p h$ account for the partial attenuation coefficients of water, gilvin, tripton and

Corresponding author: Juan F Facetti-Masulli, professor emeritus, research fields: environmental chemistry \& geochemistry, radionuclides, limnology. phytoplankton [2]. It has been shown that changes of non algal coefficients (background attenuation) play important roles in the light regime [3-5].

The Secchi disc is used to obtain the transparency and a value for the attenuation coefficient $K t$, by lowering the disc into the water until it just disappears; then raising the disc until it just appears and noting the mean distance $D_{S}$ (Sechi distance). The coefficient is given by the classical relation as noted [6] in 1929 by Poole and Atkins $K t=C x D^{-1}$ where $C$ is a factor estimated supposedly as a constant, applicable in all water bodies: $C=K x D=1.7$. However this is not the case and the value of $K x D$ varies according to water characteristics, as can be seen when for comparison a submersible photometer is employed.

Other values of $C$ have been proposed by several workers inter alia in an interesting and well documented article onto 58 lakes from Alaska and related Canadian's [7], taking into account their light regimes through Secchi distance, photometric measurements and their relationship. In lakes classified as stained, clear and turbid, the $C$ median found was 2.70, 1.86, 0.93, respectively. Farther it should be mentioned the annual variability of the product $K x D$ as has been registered in other water bodies of Alto Paraná [8] and was studied recently 
onto the Sau Reservoir in Spain [9]: $C$ values ranging from 1.49 in 1999 to 1.94 in 2000.

El Lago de la República (LdR) or República Lake is located at Ciudad del Este, in Eastern Paraguay [10], in between parallels S $25^{\circ} 30^{\prime} 39.4664^{\prime \prime}$ and S 25 $31^{\prime}$ 39.8505"; meridians W54 $37^{\prime} 01.9982^{\prime \prime}$ and W54 $37^{\circ} 27.1260^{\prime \prime}$. It was originally designed for landscape purpose but then as the source of drinking water provision to the population of that city.

It is a small reservoir formed by the impoundment of Amambay Brook, fed also by several springs though. Some physical and chemical aspects of its limnology, were published recently $[11,12]$. The water mirror covers an area of $\sim 26$ hectares with a volume of $0.8 \times 10^{6} \mathrm{~m}^{3}$. Amambay Brook a stream with average discharge of $\sim 220 \mathrm{~L} / \mathrm{s}$, flows north on basaltic residual laterites soil rich in secondary sesquioxides of $\mathrm{Fe}, \mathrm{Al}$, etc. (Latosol-Oxisol) of the Alto Paraná Formation [13]. Under rainfall, runoff incorporates detritus materials and significant amount of sediment rich in iron compounds easily hydrolyzed to produce hydrated ferric oxides, limonite $\left(\mathrm{FeOOH} . \mathrm{nH}_{2} \mathrm{O}\right)$ and polynuclear species of iron as gels [14]. The presence of these hydrous oxides in colloidal form into the lake gives the water its reddish-brown and often muddy appearance.

After some heavy rainfalls, advantage was taken to look for the effect of such compounds onto transparency i.e., the Secchi distance $D s$, the light attenuation coefficient $K$ of the water and their relationship. In addition, the composition of sediments in iron compounds was analyzed.

\section{Experiment}

The transparency/absorbance of the water was determined using both, the Secchi disc and a submergible photometer. The disc was $20 \mathrm{~cm}$ in diameter with opposing black and white quarters; the attenuation coefficient $K s$ (Secchi) was calculated according $K s=C x D^{-1}$.

The photometer employs a cadmium sulphide photo resistor; the $C d S$ cell used in these measurements is quite insensitive to radiation outside the range 400 to $700 \mathrm{~nm}$; underwater the cell responds to the ambient radiation within this band. The measurements were made at successive $d$ values lowering the photometer into water body. Since the $C d S$ detector was employed so as to detect diffuse radiation, the coefficient obtained with this device in the routine investigations was determined from:

$$
K p h=\left(\ln I_{2} / I_{1}\right) / d_{2}-d_{1}
$$

where, $I_{1}$ and $I_{2}$ are the initial and final beam of radiation measured at distances $d_{1}$ and $d_{2}$ taking the values of $\Delta d$ as short as possible.

Field measurements were made simultaneously with aforementioned instruments.

\section{Results and Discussion}

Field measurements such as shown here in Lago de la República, indicate that the actual absorption is mainly due to suspended matter, especially aqueous colloidal gel in the form of hydrated iron oxides, and that these mask the absorption due the water itself and to the phytoplankton at the conditions of experiments.

Although quanta absorption by tripton commonly is low, their scattering can be high producing [3] pronounced effects on $K$ value. This coefficient is the sum of the absorption and scattering; the distribution of particles according to size is hyperbolic; and the smaller are the most numerous; larger have high efficiency for scattering; the scattering cross section $\left(\sigma_{\mathrm{s}}\right)$ is high, in many cases larger than the geometric $\left(\sigma_{\mathrm{g}}\right)$; thus the ratio $\sigma_{\mathrm{s}} / \sigma_{\mathrm{g}}$ is greater than 1 . In the case of Lago de la Republica, the tripton affects on water transparency heavily.

(a) Following an intense rainfall of more than 100 $\mathrm{mm}$, measurements of light penetration with the photometer were made on successive time intervals. The results are break down in Table 1 that shows the $K p h$ values measured at $D s$ depth. Their relationship is expressed in the Eq. (1); they show a strong exponential correlation $R^{2}=0.9663$. 
Table 1 Photometer measurements results.

\begin{tabular}{lll}
\hline Time (days) & Dsec. $(\mathrm{m})$ & Kphot $\left(\mathrm{m}^{-1}\right)$ \\
\hline 5 & 0.4 & 4.03 \\
10 & 0.48 & 2.96 \\
12 & 0.6 & 2.65 \\
15 & 0.75 & 1.95 \\
17 & 0.95 & 1.58 \\
23 & 1.2 & 1.19 \\
\hline & $K p h=6.344 \mathrm{e}^{-1.4458 \mathrm{Ds}} R^{2}=0.9663$
\end{tabular}

(b) As the $C$ value of the relation $C=K x D$ depends on the physics and chemistry of the seston as well as dissolved stains, in this case the value $C=1.6$ fits very well with collected data. Table 2 presents the $K s$ obtained using this value.

The calculated coefficient $K s$ vs. Secchi distance $D s$ presents an analogous exponential relationship using $C=1.6$, with a very strong correlation as well. The equation and correlation factor are:

$$
K s=6.3122 \mathrm{e}^{-1.3544 \mathrm{Ds}} R^{2}=0.9761
$$

In addition these values indicate that the recovery time of LdR after a heavy rainfall is about 23 days.

The variations of photometer and Secchi attenuation coefficients with the transparency are shown in Figs. 1 and 2 .

Besides, both coefficients inter them, present a linear correlation:

$$
K p h=0.9835 K s-0.0715 \quad R^{2}=0.9907
$$

Further, and just to check the above relationships, from Hydroconsult data repository have been taken a few results of $K p h$ measured after heavy rainfalls, before the impoundment of Itaipu Dam, in Paraná River and in some of its tributaries that flow on the Alto Paraná Formation, and compared (Table 3) with herein results.

The produced equations regarding both coefficients are:

$$
\begin{array}{ll}
K p h=3.834 \mathrm{e}^{-0.709 D s} & R^{2}=0.8515 \\
K s=4.1845 \mathrm{e}^{-0.76074 \text { Ds }} & R^{2}=0.9761
\end{array}
$$

The variations of the attenuation coefficients $K p h$ and $K s$ are exposed in Fig. 3.

Besides, taken in account that the aim of this work is to evaluate the influence of the Fe content on the
Table 2 Calculated $K s$ values.

\begin{tabular}{lll}
\hline Time (day) & Dsec. $(\mathrm{m})$ & Ksec. $\left(\mathrm{m}^{-1}\right)$ \\
\hline 5 & 0.4 & 4 \\
10 & 0.48 & 3.3 \\
12 & 0.6 & 2.67 \\
15 & 0.75 & 2.13 \\
17 & 0.95 & 1.68 \\
23 & 1.2 & 1.33 \\
\hline
\end{tabular}

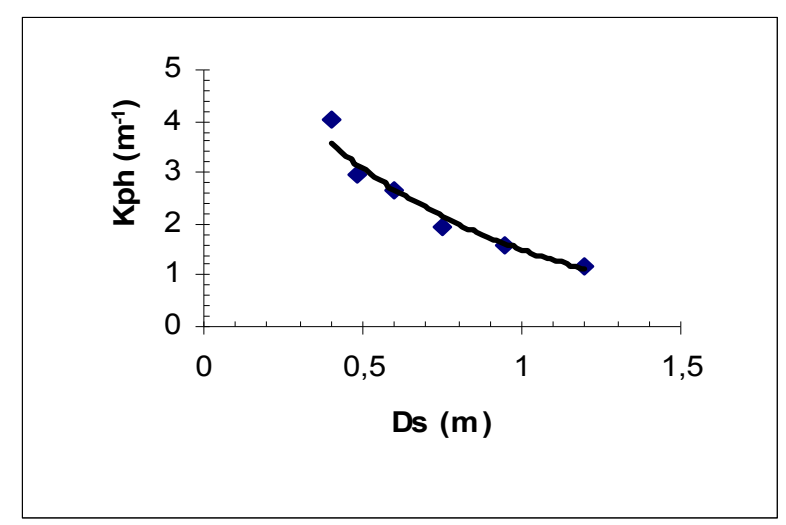

Fig. 1 Photometer attenuation coefficient (Kph) vs. transparency.

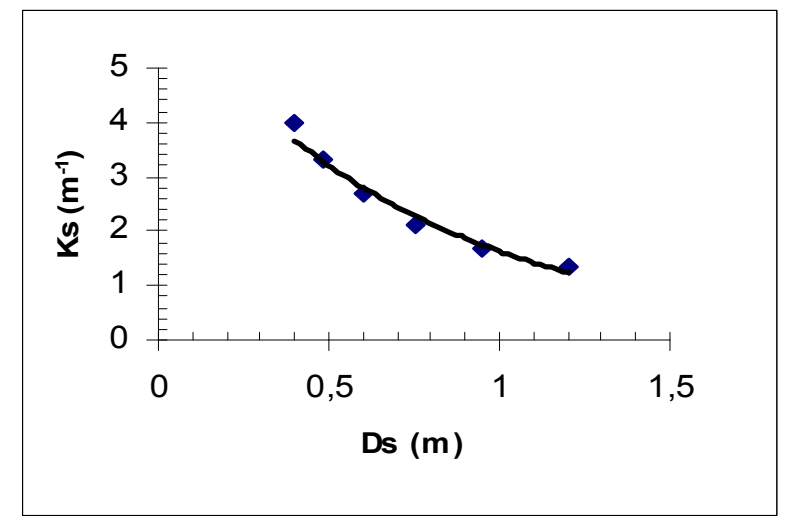

Fig. 2 Secchi attenuation coefficient (Ks) vs. (Ds) transparency (Ds).

Table 3 Measured $K p h \&$ calculated $K s$ at $D s$.

\begin{tabular}{llll}
\hline Site & D & Kph & Ks \\
\hline LdR & 0.4 & 4.03 & 4 \\
LdR & 0.48 & 2.96 & 3.33 \\
It & 0.55 & 3.3 & 2.9 \\
RP & 0.6 & 2.71 & 2.7 \\
RP & 0.7 & 1.85 & 2.28 \\
LdR & 0.75 & 1.95 & 2.13 \\
LdR & 0.95 & 1.58 & 1.68 \\
LdR & 1.2 & 1.19 & 1.33 \\
RP & 2.8 & 0.61 & 0.57 \\
\hline
\end{tabular}

It = Itabo River; RP: Paraná River. 
Table 4 Registered Fe content at $D s$ in Alto Paraná River.

\begin{tabular}{llll}
\hline Ds $(\mathrm{m})$ & $\mathrm{Fe}(\mathrm{mg} / \mathrm{L})$ & $\mathrm{Ds}(\mathrm{m})$ & $\mathrm{Fe}(\mathrm{mg} / \mathrm{L})$ \\
\hline 0.1 & 10 & 0.5 & 0.25 \\
0.1 & 4.15 & 0.55 & 1.13 \\
0.15 & 9.2 & 0.6 & 3.31 \\
0.2 & 4.3 & 0.8 & 0.88 \\
0.25 & 3.6 & & \\
0.3 & 2.2 & & \\
0.3 & 2 & & \\
0.35 & 1.62 & & \\
0.35 & 2.8 & & \\
\hline
\end{tabular}

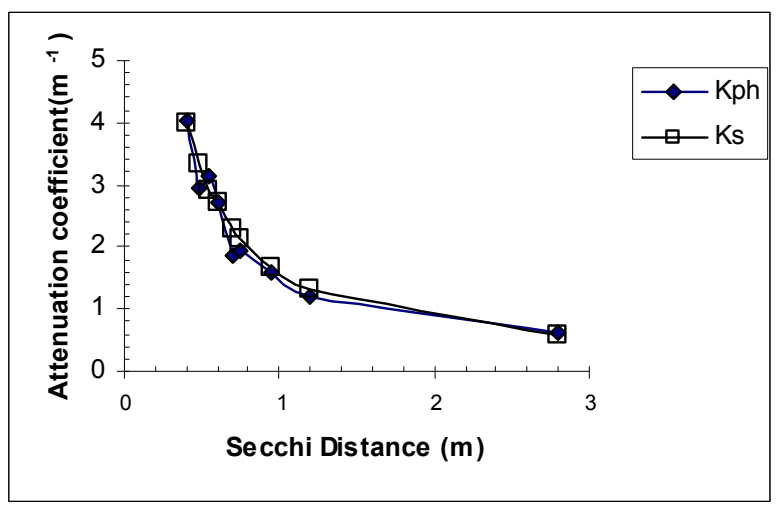

Fig. 3 Variation of both, photometer and Secchi attenuation coefficients with transparency.

SS (suspended sediments), from our data bank have been selected results regarding their $\mathrm{Fe}$ content and the registered Secchi distance $D s$ in Alto Paraná River, as is breakdown in Table 4. They present an interesting polynomial relationship:

$$
\begin{gathered}
\mathrm{Fe}=27.724 \mathrm{D}^{2}-32.92 \mathrm{D}+10.492 \\
\text { with } R^{2}=0.64
\end{gathered}
$$

This confirms the strong influence of $\mathrm{Fe}$ concentration in SS on quanta absorption and shows that the lesser the Fe content (more transparency), the contribution of $\mathrm{SiO}_{2}$ and other seston materials to the light attenuation become more relevant.

In the lake, very little of dissolved $\mathrm{Fe}^{3+}$ exists. At $\mathrm{pH}=1$ and below, $\mathrm{Fe}^{3+}$ is present in dissolution as an aquo complex; increasing the $\mathrm{pH}$ the compound tends to hydrolyze (stepwise) to the more stable [15] chemical forms as $\left[\mathrm{Fe}\left(\mathrm{H}_{2} \mathrm{O}\right)_{5} \mathrm{OH}\right]^{2+}\left(\mathrm{Ke}=6.5 \times 10^{-3}\right)$ and other limonitic varieties as well as polynuclear compounds. In the Republica Lake, the $\mathrm{pH}$ oscillates between 6-7; at a $\mathrm{pH}$ value of $6.8(\sim$ average of field campaigns in $\mathrm{LdR}$ ), the concentration of $\mathrm{Fe}^{3+}$ in dissolution is only about of $\sim 10^{-8} \mathrm{~mol} / \mathrm{L}$ as can be easily calculated from the equilibrium constants Ke of hydrolysis successive reactions. Thus, precipitate the very insoluble [16] colloidal gels of $\mathrm{Fe}^{3+}$ hydrous oxides that due of charge - transfer bands mainly in the UV region as well as a little in the visible, give the Lake its typical reddish-yellow brown and "often muddy appearance".

In a side test, samples of water taken from the Lago de la Repùblica during periods of high turbidity, when left undisturbed in the laboratory in tall graduate cylinders for periods exceeding 60 days shown no complete settling and led to of a colloid sol subject to Brownian motion. Materials settled showed very little if any, of colloidal nature.

The composition of sediments during its "aging" starts with freshly precipitated colloids of $\mathrm{Fe}(\mathrm{OH})_{3}$ that transform into the more stable oxihydroxides, ending with hematite $\alpha \mathrm{Fe}_{2} \mathrm{O}_{3}$. Taken into account that the smaller the solubility product $K s$, the larger the stability of the compound, the series could be arranged, as stated in Ref. [15], according to their $K s$ as follows:

$$
\begin{aligned}
& -\log K s \quad 37.5-39.5 \quad 38.9-40.9 \quad 38.8-40.8 \\
& \mathrm{Fe}(\mathrm{OH})_{3}-\rightarrow \gamma \mathrm{FeO} \mathrm{OH} \mathrm{(ccp)-} \rightarrow \gamma \mathrm{Fe}_{2} \mathrm{O}_{3} \text { (ccp) }-\rightarrow \\
& \alpha \mathrm{FeO} \mathrm{OH} \mathrm{(hcp)- \rightarrow} \rightarrow \mathrm{Fe}_{2} \mathrm{O}_{3}(\text { hcp }) \\
& -\log K s \text { 40.0-42.1 } 40.3-43.0
\end{aligned}
$$

The values of $-\log K$ indicate the stability ranges of the compounds; inter allia poorly crystalline are less stable than well crystalline species/forms [17]. The evolved changes are topotactic (solid satate) transformations; short range order in long range disorder, irregular lattice perturbations as well as its formation [18] and active/extended surfaces play their role. These transformations are favored as the ccp (cubic close packed) and hcp (hexagonal close packed) structures are closely related.

In regard to the presence of $\mathrm{Fe}^{2+}$ in the sediments, samples were submitted to Mossbauer measurements which were made by absorption spectrometry using a 57 Co-source and a proportional Xe counter. The data 
were collected with a MCA. After regression of lorentzian curves from the spectra, for each line, the intensity and velocity of maximum absorption and the FWHM were determined. The spectra measured at $77+\mathrm{K}$, show a doublet with IS of $0.3 \mathrm{~mm}$ and QS of $0.60 \mathrm{~mm}$ in the samples, corresponding to high spin $\mathrm{Fe}^{3+}$. No signal of $\mathrm{Fe}^{+2}$ was observed at the conditions of these measurements.

\section{Conclusions}

It is safe to use $C=1.6$ in order to calculate attenuation coefficient when performing transparency measurements in inland waters with their tripton loaded by colloidal material rich in ferric hydrous oxides, as seen in fresh water bodies running/seated on basaltic residual lateritic soils rich in secondary sesquioxides of $\mathrm{Fe}$ from basalts effusions. Besides, the iron element is present in the oxides/ hydrous oxides of the suspended sediments as $\mathrm{Fe}^{3+}$.

\section{Acknowledgment}

Thanks are due to Prof. R. Velazquez for the Mossbauer experiments.

\section{References}

[1] A.F. Cambridge Research Center, Geophysics Research Directorate. 1957. Handbook of Geophysics for Air Force Designers. First Edition, New York: Macmillan, 16-9.

[2] Kirk, J. T. O. 1986. Light and Photosynthesis in Aquatic Ecosystem. Cambridge: Cambridge University Press, 42-90.

[3] Fitzpatrick, J. A. 1982. "Physical Limnological Measurements in the Alto Parana Region of Eastern Paraguay." Doctoral Dissertation, Anthony University, 35-6.

[4] Elser, J. J. 1987. "Evaluation of Size-Related Changes in Chlorophyll-Specific Light Extinctions in Some North Temperate Lakes.” Arch. Hydrobiol. 111: 171-82.

[5] Bowling, L. C. 1988. "Optical Properties, Nutrients and
Phytoplankton of Freshwater Coastal Lakes in Southeast Queensland." Australian J. Mar. Freshwater Res. 39: 805-15.

[6] Poole, H. H., and Atkins, W. R. 1929. "Photo-Electric Measurements of Submarine Illumination throughout the Year." J. Mar. Biol. Assoc. 16: 297-394.

[7] Koenings, J. P. and Edmundson, J. A. 1991. "Secchi Disk and Photometer Estimates of Light Regimes in Alaskan Lakes." Limnol. Oceanogr. 36: 91-105.

[8] Facetti-Masulli, J. F. 1987. "Itaipu Dam Limnological Studies in the Right Side of the Reservoir: Part I." In Second Seminar of Itaipu Binacional on Environment. Brazil: Foz do Iguazu, 153-67. (In Spanish).

[9] Armengol, J., Caputo, L., Comerma, M., Feijoó, C., García, J. C., Marcé, R., Navarro, E., and Ordoñez, J. 2003. "Sau Reservoir's Light Climate: Relationships between Secchi Depth and Light Extinction Coefficient." Limnetica 22: 195-210.

[1 0 ] National Carte. 1985. Planimetric Report on 1984. Aerial Photographs: Geographic Military Institute 5370 II.

[11] Facetti-Masulli, J. F., López, C., Delgado, M., and Fitzpatrick, J. 2014. "Limnology of the Republic Lake I." J. of Scientific Society of Paraguay. 19: 179-85. (In Spanish).

[12] Facetti-Masulli, J. F., López, C., and Delgado, M. 2015. "Limnology of the Republic Lake II." J. of the Scientific Society of Paraguay. 20: 75-84. (In Spanish).

[13] Facetti-Masulli, J. F., Kump, P., and Díaz Z. V. de. 2003. "Selected Trace and Minor Elements in Sediments of Itaipú dam." Czechoslovac J. of Physics. 53: 209-15.

[14] Cotton, F. A., and Wilkinson, G. 1985. Advanced Inorganic Chemistry. New York: John Wiley \& Sons.

[15] Appelo, C. A., and Posma, D. 2005. Geochemistry, Groundwater and Pollution. Amsterdam: AA Balkema Publishers.

[16] VanLoom, G. W., and Duffy, S. J. 2000. Environmental Chemistry. Oxford: Oxford University Press.

[17] Majzlan, J. et al. 2002. "Thermochemistry of Poorly Crystal Line Compounds." Presented at Goldschmidt Conference. A477.

[18] Hückel, W. 1953. Structural Inorganic Chemistry. Reverte Ed. Barcelona. (In Spanish). 